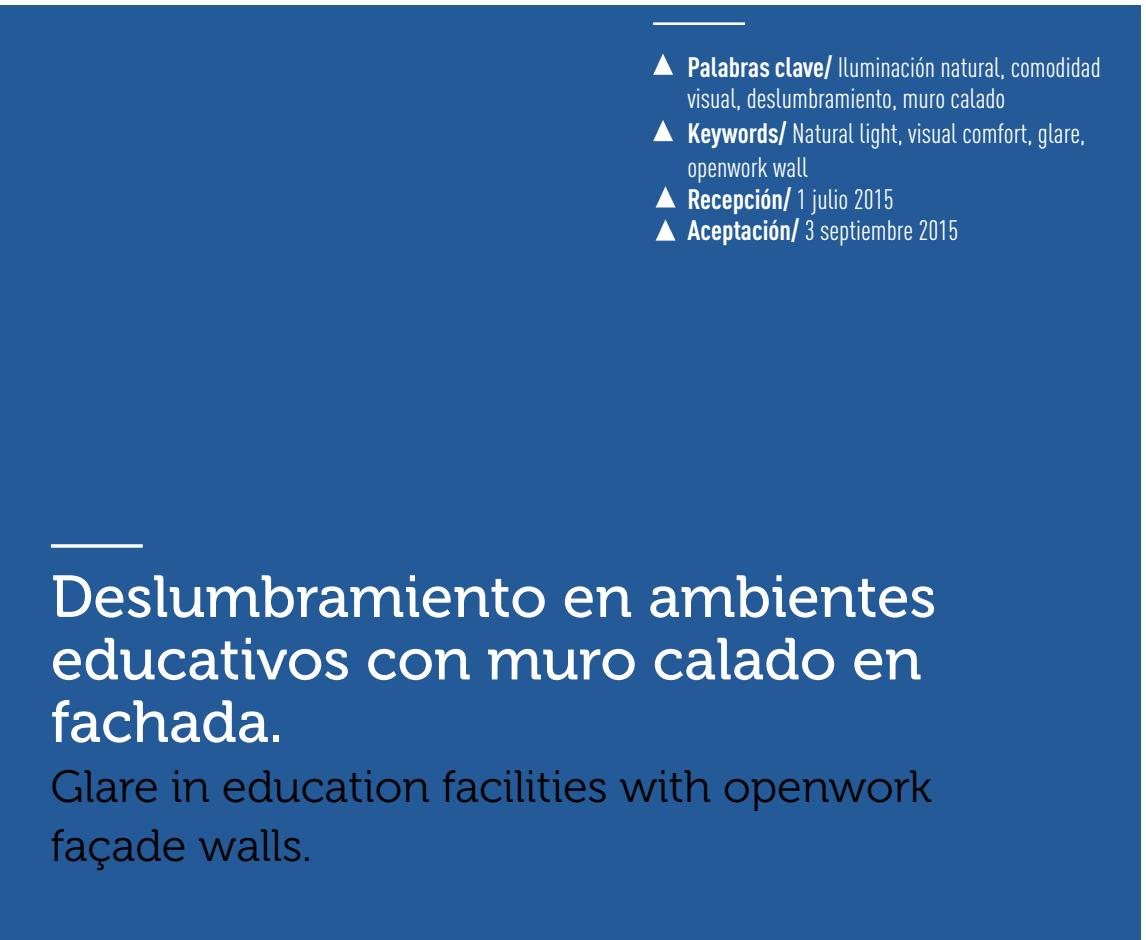

\begin{abstract}
Lucas Arango-Díaz
Arquitecto, Universidad Nacional de Colombia.

Magister en Arquitectura y Urbanismo,

Universidade Federal de Santa Catarina, Brasil.

Académico, Universidad de San Buenaventura Medellín

lucas.arango@usbmed.edu.co
\end{abstract}

RESUMEN/ La implementación de muros calados en edificaciones localizadas en lugares con clima cálido es una práctica común, pues resulta ser una estrategia relativamente económica para favorecer la ventilación natural y el control solar. A pesar de los beneficios de la inclusión de la iluminación natural en ambientes educativos, no hay suficientes estudios que caractericen, desde el punto de vista de la comodidad visual, salones de clases con muros calados en fachada. Esta investigación tiene por objetivo revisar el desempeño, en términos de la probabilidad de deslumbramiento y de la admisión de la luz natural, en ambientes educativos hipotéticos con muros calados en fachada y localizados en Cali (lat. $3^{\circ} 26^{\circ}$, long. $-76^{\circ} 31^{\circ}$ y alt. 995 m.s.n.m.), Colombia. Para lograr esto, fueron realizadas simulaciones computacionales haciendo uso del plugin Diva for Rhino. Los resultados evidencian el potencial del uso de superficies perforadas en ambientes educativos en localidades geográficas con clima cálido. ABSTRACT/ Openwork walls are common in buildings located in warm weather settings. It is a relatively cheap strategy to favor natural ventilation and sun control. In spite of the benefits of including natural light in educational facilities, there are only a few studies characterizing classrooms with openwork façade walls from the point of view of visual comfort. This research is aimed at reviewing the performance, in terms of the glare likelihood and the access of natural light, in hypothetical education contexts with openwork façade walls, and located in Cali (lat. $3^{\circ} 26^{\prime}$, long. - $76^{\circ} 31^{\circ}$ and. 995 m.a.s.l.), Colombia. To achieve this, computer simulations with the Diva for Rhino plugin were done. The evidence suggests the potential of using perforated surfaces in educational facilities in geographical locations with hot weather.

\section{BIOCLIMÁTICA Y COMODIDAD}

VISUAL. La Bioclimática' ha ido progresivamente retomando importancia en el quehacer del arquitecto contemporáneo. Ese nuevo impulso se ha visto fortalecido por la imperiosa necesidad de mitigar los daños ecológicos y crisis ambientales que, según Maslin (2009), afectan principalmente a los sectores con menos recursos económicos de la sociedad. En parte, esos daños y crisis son suscitados por la emisión de gases de efecto invernadero derivados de las actividades de diseño y construcción, y de la forma de habitar los ambientes. En general, se estima que $33 \%$ del total de las emisiones de gases de efecto invernadero provienen de actividades relacionadas con la construcción (La Roche 2012). Para disminuir la excesiva dependencia de la energía eléctrica de las edificaciones y minimizar la emisión de gases de efecto invernadero, Gulati (2012) reconoce que el control térmico interior depende, en gran medida, del adecuado diseño de sistema de fachada y, por tanto, también depende de ello la energía necesaria para garantizar condiciones de comodidad térmica. La autora evidencia que, sumado a la integración de paneles fotovoltaicos para generar energía, la incorporación de estrategias desde fases iniciales del proceso arquitectónico hace posible una reducción significativa de las ganancias de calor, lo que implica un menor consumo de energía eléctrica. 

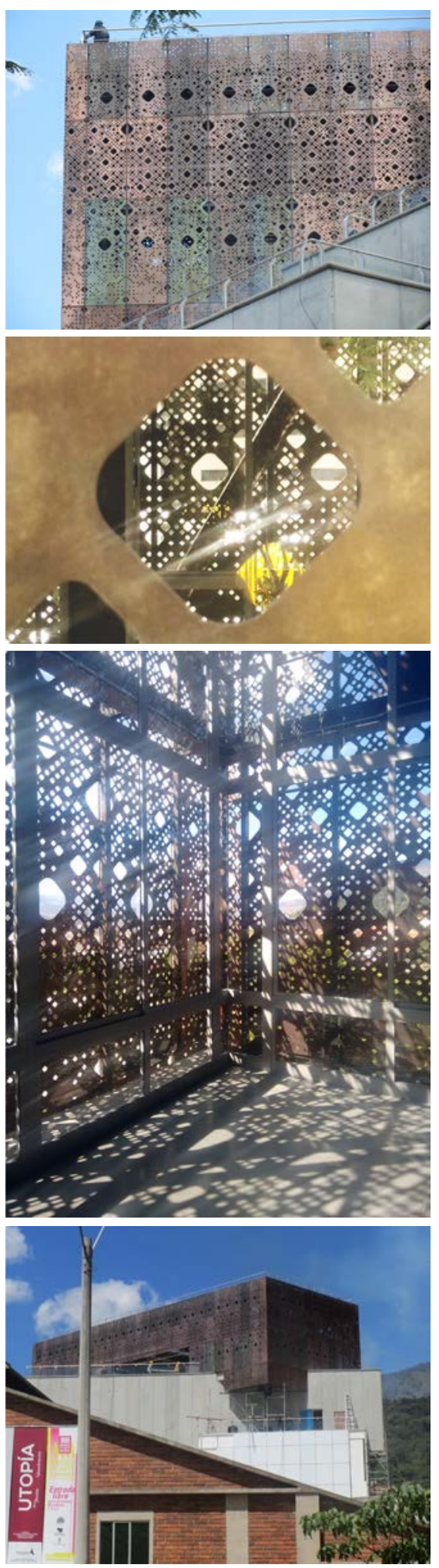

Imagen 1. Fachada en construcción del Museo de Arte Moderno de Medellin - MAMM (fuente: El autor 2015)

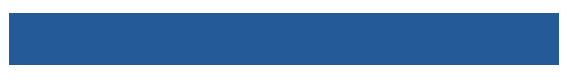

\section{LAS SUPERFICIES PERFORADAS Y LA COMODIDAD VISUAL. En la}

actualidad, en localidades geográficas con clima cálido, es común la implementación de superficies perforadas en las fachadas de las edificaciones. El uso de este recurso arquitectónico obedece, principalmente, a la necesidad de favorecer la comodidad térmica interior a través de ventilación natural constante y el control solar sin incrementar excesivamente costos constructivos y de mantenimiento (Salazar y Rendón 2012).

Históricamente, este recurso arquitectónico fue muy utilizado en la cultura árabe a través de los tradicionales Mashrabiya. Éstos se utilizaron no únicamente por razones relacionadas con la optimización térmica y

Si bien es cierto que el uso de energías limpias y de eficiencia energética es el que ha impulsado el nuevo reconocimiento de la bioclimática, se han abierto, en el marco de la comodidad ambiental, cuestionamientos e investigaciones relacionadas con los beneficios psicológicos y fisiológicos de ambientes naturalmente iluminados. Ambientes iluminados naturalmente generan en sus ocupantes mayor productividad y rendimiento laboral o académico, sensación de bienestar, control de la temporalidad, conexión con las condiciones climáticas y control del ciclo circadiano (Boubekri 2008; Meek y Van den Wymelenberg 2015; Steg, Vand Den Berg y De Groot 2013).

No obstante, iluminar naturalmente un ambiente interior de manera 'correcta', necesariamente requiere de reflexiones y estrategias previas de parte del diseñador, relacionadas con la comodidad visual. Este concepto hace referencia a "la existencia de un conjunto de condiciones, en determinado ambiente, con las cuales el ser humano puede desarrollar sus tareas visuales con máxima agudeza y precisión visual, con mínimo esfuerzo y con reducido riesgo de accidentes o perjuicios a la vista" (Lamberts, Dutra y Pereira 2014). Por tanto, las reflexiones antes mencionadas tienen que ver con la cantidad y calidad de luz natural necesaria, la distribución lumínica interior, control de brillo y contraste en el campo visual de los ocupantes y el control de los colores, entre otras. Todas ellas trascienden el hecho de, simplemente, disponer sistemas de fachadas, incluyendo por ejemplo, superficies perforadas únicamente a partir de criterios estéticos o presupuestales. el aprovechamiento lumínico, sino también, se presume, para el control visual y la protección de la intimidad (Nunes 2015). Entre las superficies perforadas, principalmente en localidades geográficas con predominancia de sistemas tradicionales de construcción, se destacan los muros calados -conocidos en Brasil como Cobogós- que consisten en superficies mampuestas constituidas por bloques con perforaciones horizontales. Actualmente, esta reinterpretación moderna de las superficies perforadas constituye, en localidades geográficas de climas cálidos, una solución con alto potencial en ambientes educativos que atienden a sectores económicamente poco favorecidos, que son incapaces de pagar el uso de aire acondicionado

Ruggiero, Serra y Dimundo (2009), a partir del análisis comparativo de la reinterpretación de las fachadas típicas del estilo mediterráneo (abertura única y centralizada en la pared) y del estilo islámico (distribución de varias aberturas en la pared), identificaron el potencial que tiene la segunda para disponerse en ambientes destinados a realizar actividades típicas de oficina, en la medida en que posibilita una distribución lumínica más uniforme, disminuye la posibilidad de contrastes y posibilita mejores visuales al exterior (imágenes 1 y 2).

A pesar del potencial descrito, este recurso arquitectónico ha sido escasamente estudiado desde el punto de vista bioclimático (Salazar y Rendón 2012; Salazar 2015) especialmente desde la perspectiva de la comodidad visual. En ambientes 


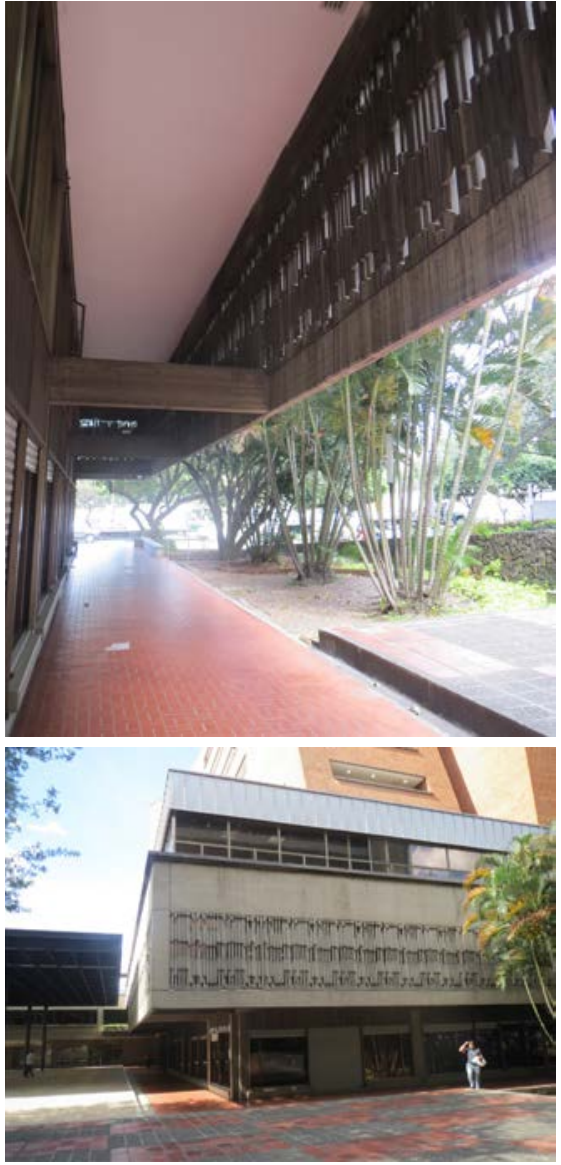

Imagen 2. Edificio Suramericana, Medellin (fuente: El autor 2015). educativos localizados en el trópico, la falta de estudio no ha imposibilitado la implementación de este recurso en fachadas, tal como se ejemplifica en imagen 3

Admisión/distribución lumínica de ambientes educativos con muros

calados. A pesar de todas las implicaciones que pueda traer la implementación de aberturas en la fachada sobre la comodidad visual de los ocupantes de determinado ambiente, es común que las recomendaciones de su disposición, tamaño, localización, entre otras, atiendan únicamente requerimientos relacionados con el nivel lumínico recomendado para realizar determinada tarea visual. En el capítulo 7,2 de la Norma Técnica Colombiana (NTC) 4595 (1999), se indica que "esta norma hace énfasis en la provisión de luz natural, de tal forma que durante la mayor parte de la jornada escolar puedan satisfacerse los requerimientos de iluminación sin necesidad de utilizar fuentes de iluminación artificial”. A pesar de que el título del subcapítulo se refiere a la comodidad visual, este texto, sumado a la serie de recomendaciones establecidas en el documento, evidencia una falta de reflexión en torno a temas relacionados con todo el espectro de la comodidad visual y una preocupación casi exclusiva por la eficiencia energética (Arango, Giraldo, Cano y Arenilla 2013)
La imagen 4 muestra el resultado de simulaciones computacionales de admisión y distribución luminosa, realizadas sobre tres ambientes educativos localizados en Cali-Colombia (lat. 326', long. - $76^{\circ} 31^{\prime}$ y alt. 995 m.s.n.m.). Los ambientes, de idénticas proporciones, presentan modificaciones en su fachada. Los resultados de estas simulaciones evidencian notables diferencias entre los diferentes horarios analizados de cada ambiente, pero mínimas diferencias entre los resultados en mismos horarios y diferentes tipos de fachada. Entre éstas se destaca un ligero aumento de los niveles lumínicos en la zona más profunda del salón,

\section{correspondiente a la fachada 3 .}

Deslumbramiento en ambientes educativos con muros calados. Uno de los aspectos que en la NTC 4595 (1999) y en otras normas y códigos de construcción es dejado de lado, hace referencia al deslumbramiento. Éste puede definirse como una sensación psicofisiológica de malestar visual con la distribución de áreas muy brillantes comparadas con otras menos brillantes dentro del campo visual de los ocupantes (Aksamija 2013). Dicho de otro modo, según la Illuminating Engineering Society of North America (IESNA) (2000), la sensación de deslumbramiento se produce por valores de luminancias en el campo visual mayores a las que los ojos se pueden adaptar. Hopkinson, Petherbridge
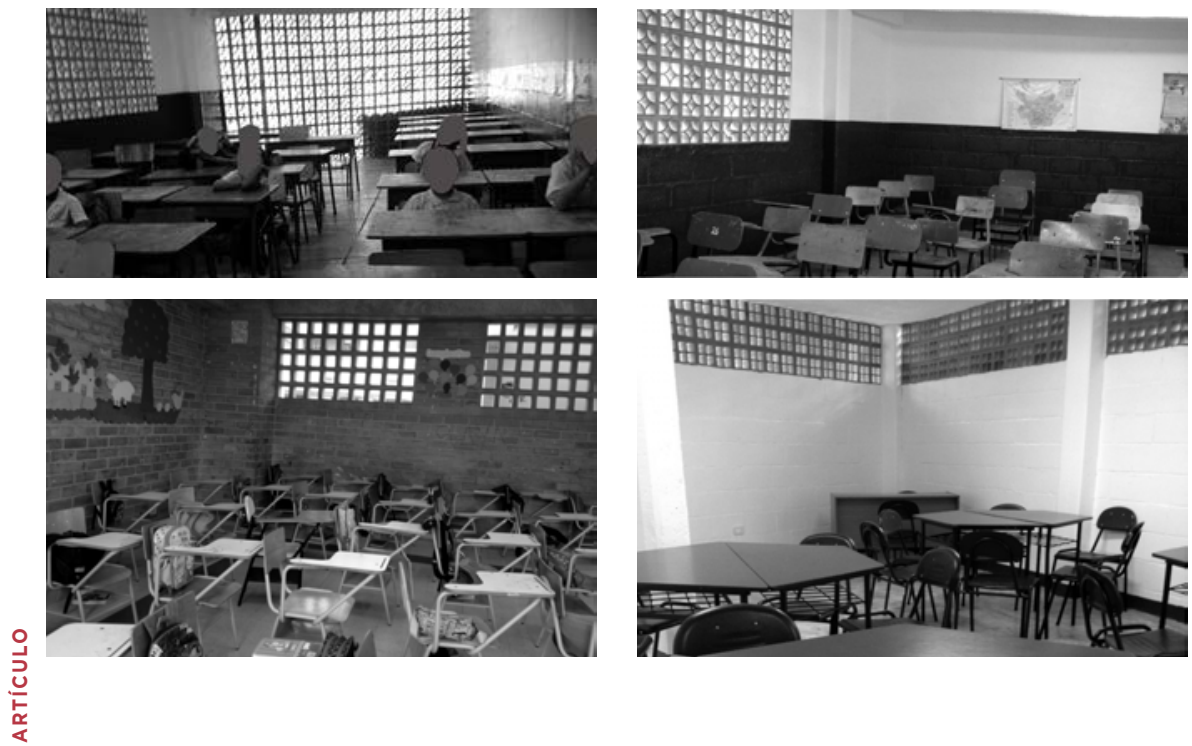

Imagen 3. Superior e inferior izquierda: Salones de la Institución Educativa La Sierra. Inferior derecha. Salon de la Institución Educativa Olaya Herrera
(fuente: Laura Camila Barón Correa). 
y Longmore (1966) señalan que, si bien el brillo es importante para la visión, su exceso puede disminuir la agudeza visual y la sensibilidad al contraste. Debido a que las reflexiones sobre deslumbramiento están necesariamente relacionadas con el campo visual resultante desde la posición del observador hacia el punto observado, a diferencia de las de admisión y distribución lumínica que se calculan sobre el plano de trabajo, es importante revisar varios observadores para los análisis de deslumbramiento.

En el caso de las imágenes aquí presentadas -en las que se muestra la distribución de uminancias en el campo visual a través de simulaciones, utilizando las mismas especificaciones en el mismo programa en el que se realizaron las simulaciones de admisión/distribución luminosa-

fueron considerados dos observadores enfocando su mirada hacia el mismo punto específico en el tablero, pero desde diferente localización al interior del salón (imagen 5). Ejemplos de estas imágenes, calculadas para septiembre 21 a las 09 horas, se muestran en imagen 6 . En ella se evidencian las diferencias en la distribución de brillos en el campo visual generadas por la composición de la fachada. Por ejemplo, para el día y la hora calculados, el muro calado (fachada 2 y fachada 3) distribuye en el campo visual las superficies más brillantes, producto del ingreso de rayos solares a través de los bloques calados y de seccionamiento de la porción de cielo visible a través de la fachada. Mientras tanto, la fachada convencional (fachada 1) concentra las superficies brillantes en una única sección del campo visual.
Imagen 4. Desempeño lumínico de tres ambientes educativos. valuaciones de los ambientes hipotéticos fue utilizado el plug-in Diva (Solemma 2015) en el programa Rhinoceros. En del archivo climatico de la ciudad de Call. Para estos cálculos se especifico que los usuarios permanecerian todo el tiempo en el ambiente y que no podrian adaptar las condiciones de la fachada a fin de modificar el ambiente. Con relación a los materiales, en el programa fueron especificados los siguientes parametros. Alero = GenericinteriorWall_50, techo = GenericCeiling_80, muros = Generic/nteriorWall_50, muros $\begin{aligned} \text { calados } & =\text { GenericInteriorWall 50, piso = GenericFloor_20, Tablero } \\ & =\text { HighReflectanceCeiling } 90 \text { (fuente: Elaboración propia) }\end{aligned}$

\section{Tipo de Fachada}
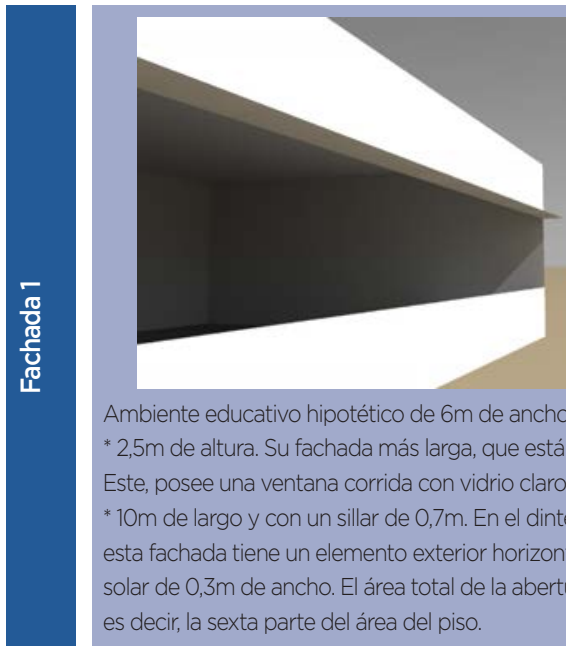

Ambiente educativo hipotético de $6 \mathrm{~m}$ de ancho * $10 \mathrm{~m}$ de largo * $2,5 \mathrm{~m}$ de altura. Su fachada más larga, que está orientada al Este, posee una ventana corrida con vidrio claro de $1 \mathrm{~m}$ de altura * $10 \mathrm{~m}$ de largo y con un sillar de $0,7 \mathrm{~m}$. En el dintel de la ventana esta fachada tiene un elemento exterior horizontal de control solar de $0,3 \mathrm{~m}$ de ancho. El área total de la abertura es de $10 \mathrm{~m}^{2}$, es decir, la sexta parte del área del piso.
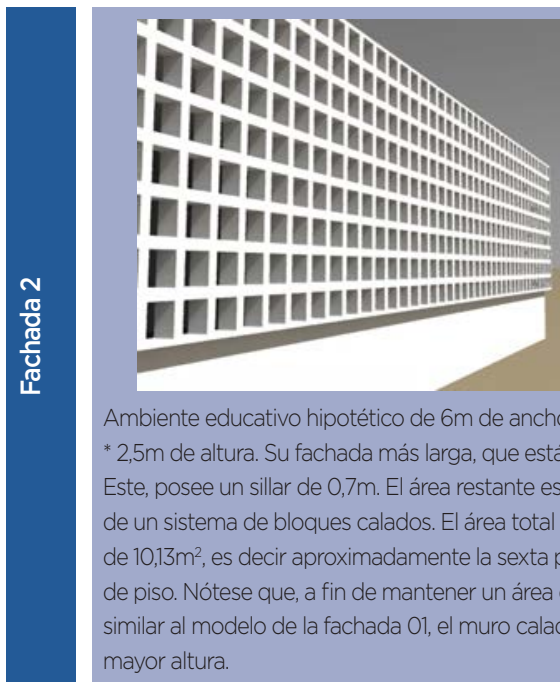

Ambiente educativo hipotético de $6 m$ de ancho * $10 m$ de largo *2,5m de altura. Su fachada más larga, que está orientada al Este, posee un sillar de 0,7m. El área restante está compuesta de un sistema de bloques calados. El área total de abertura es de $10,13 \mathrm{~m}^{2}$, es decir aproximadamente la sexta parte del área de piso. Nótese que, a fin de mantener un área de aberturas similar al modelo de la fachada $\mathrm{O1}$, el muro calado debe poseer mayor altura.
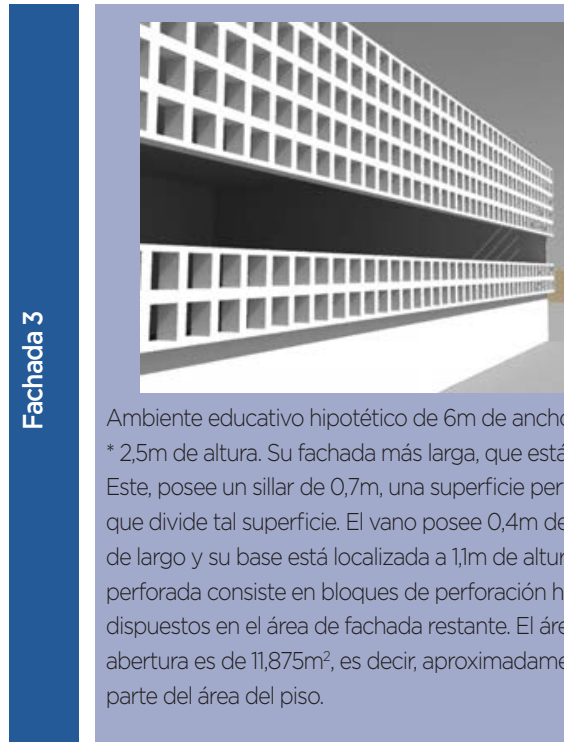

Ambiente educativo hipotético de $6 \mathrm{~m}$ de ancho * $10 \mathrm{~m}$ de largo * $2,5 \mathrm{~m}$ de altura. Su fachada más larga, que está orientada al que divide tal superficie. El vano posee $0,4 \mathrm{~m}$ de altura * $10 \mathrm{~m}$ de largo y su base está localizada a 1,1m de altura. La superficie perforada consiste en bloques de perforación horizontal dispuestos en el área de fachada restante. El área total de abertura es de $11,875 \mathrm{~m}^{2}$, es decir, aproximadamente la quinta parte del área del piso.
Nivel lumínico. Septiembre 21 . Cielo Despejado

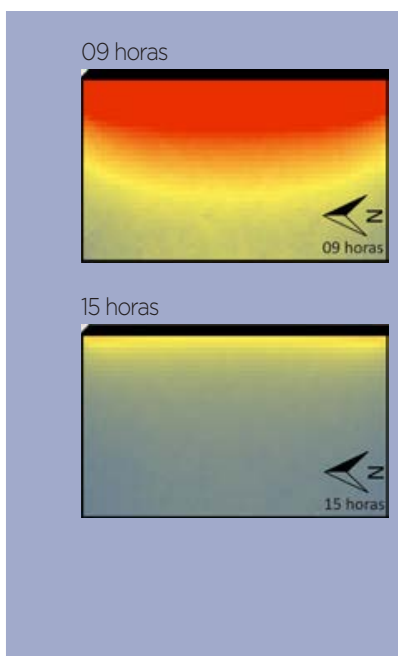

09 horas

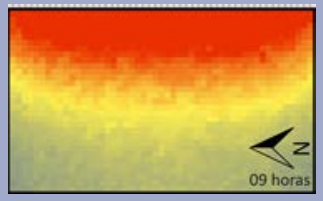

15 horas

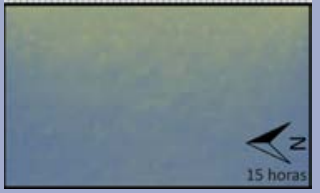

15 horas Este, posee un sillar de $0,7 \mathrm{~m}$, una superficie perforada y un vano
09 horas

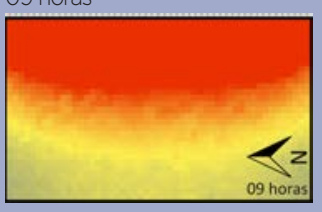

15 horas
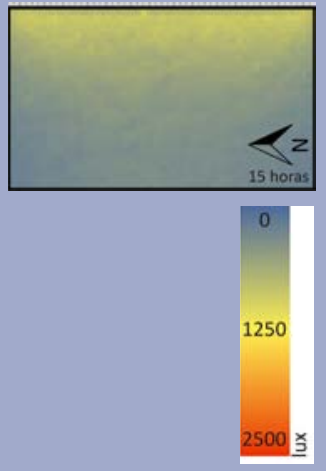


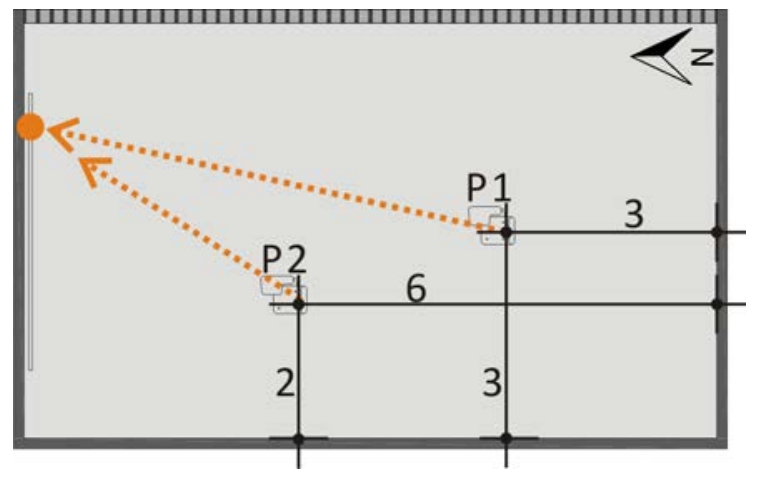

Imagen 5. Localización de observadores (P1 y P2) para análisis de des/umbramiento (fuente: Elaboración propia).

De acuerdo a Wienold (2010), existen tres tipos de deslumbramiento: incapacitante o disability glare; incómodo, perturbador o discomfort glare; y reflejos o glare reflections. No obstante, en ambientes internos en los que no se consideren pantallas u otros dispositivos similares, adquieren mayor importancia el deslumbramiento incapacitante, aquel que imposibilita la visión y el deslumbramiento incómodo o perturbador, que se percibe como una molestia pero que no impide ver. De este par, tal como lo expone Wienold (2010), el segundo adquiere un mayor protagonismo en estudios de deslumbramiento en ambientes interiores, pues se requieren menores valores de luminancia para alcanzar el deslumbramiento incómodo que el incapacitante y, por tanto, en caso de garantizar las condiciones para minimizar la posibilidad de deslumbramiento incómodo o perturbador, ya se estarían reduciendo las posibilidades para que exista la sensación de incapacidad por el deslumbramiento. En el área de prevención de deslumbramiento, varios modelos han sido implementados para identificar las molestias ocasionadas por la distribución de brillos
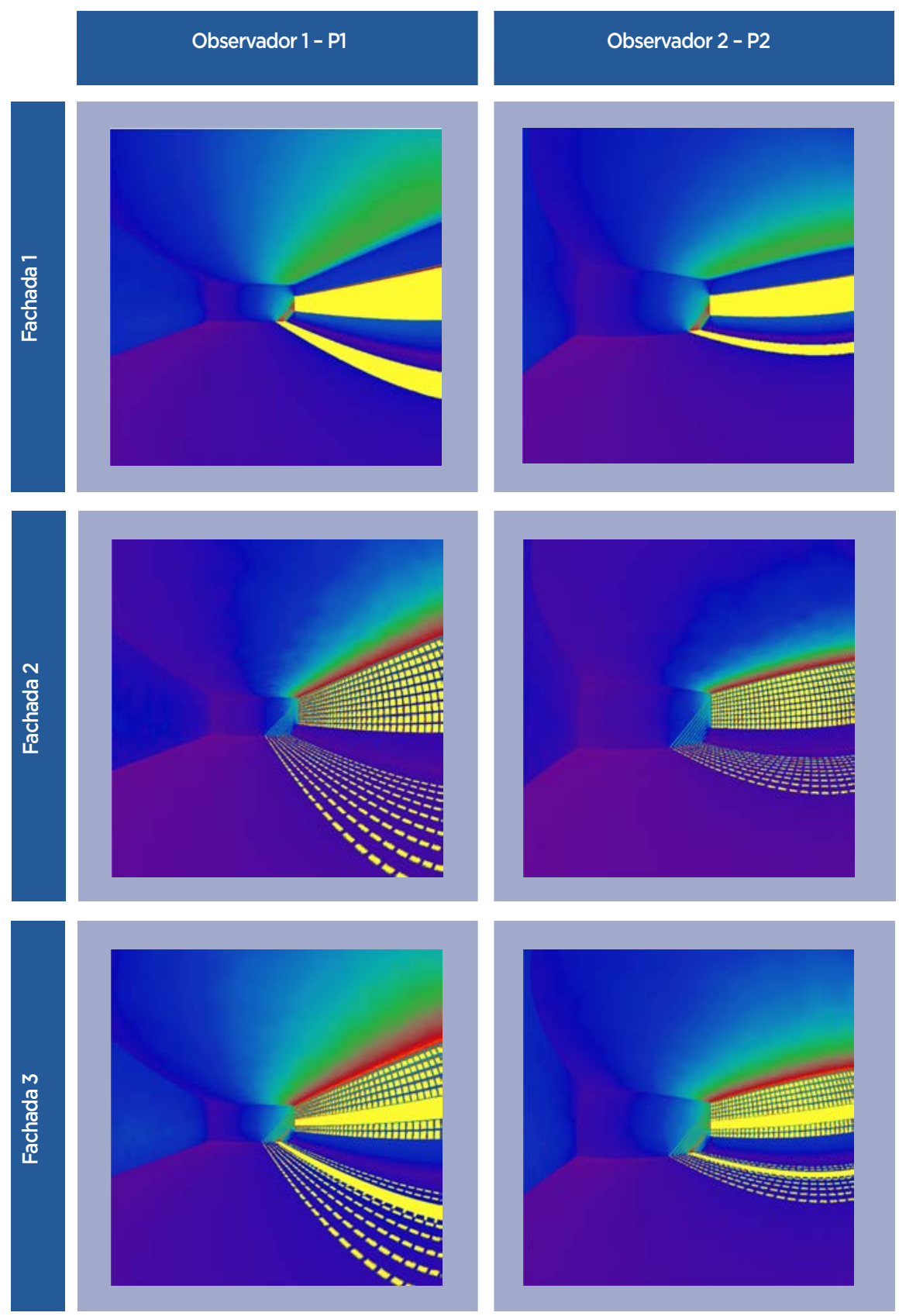

Imagen 6. Distribución de luminancias en el campo visual, con cielo despejado para Septiembre 21 - 09h, haciendo uso de una cámara fisheye $180^{\circ}$ en el plugin Diva, denominado Daylight image-Visualization (fuente: Elaboración propia. Imagen generada haciendo uso del plugin Diva for Rhino). 

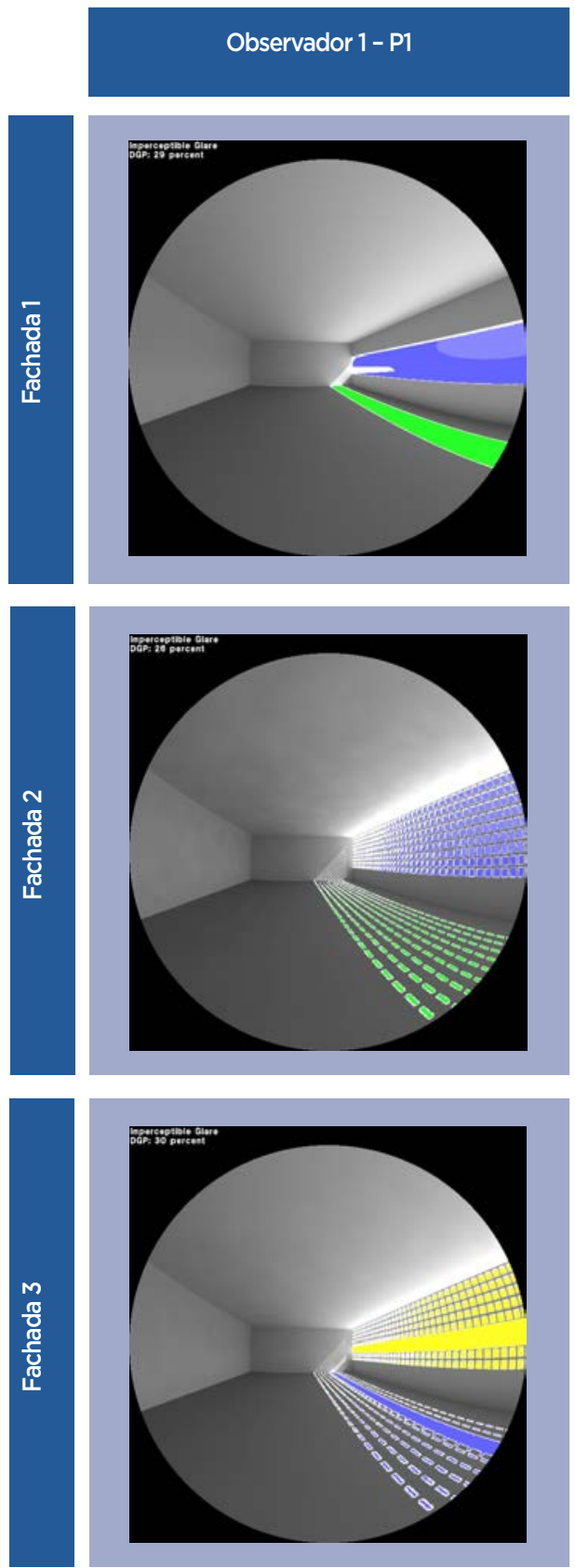

Imagen 7. Análisis de DGP para 2 observadores en 3 ambientes educativos. Análisis realizados para Septiembre 21 - O9h con condiciones de cielo despejado (fuente: Elaboración propia. Imagen generada haciendo uso del plugin Diva for Rhino).
Observador 2 - P2
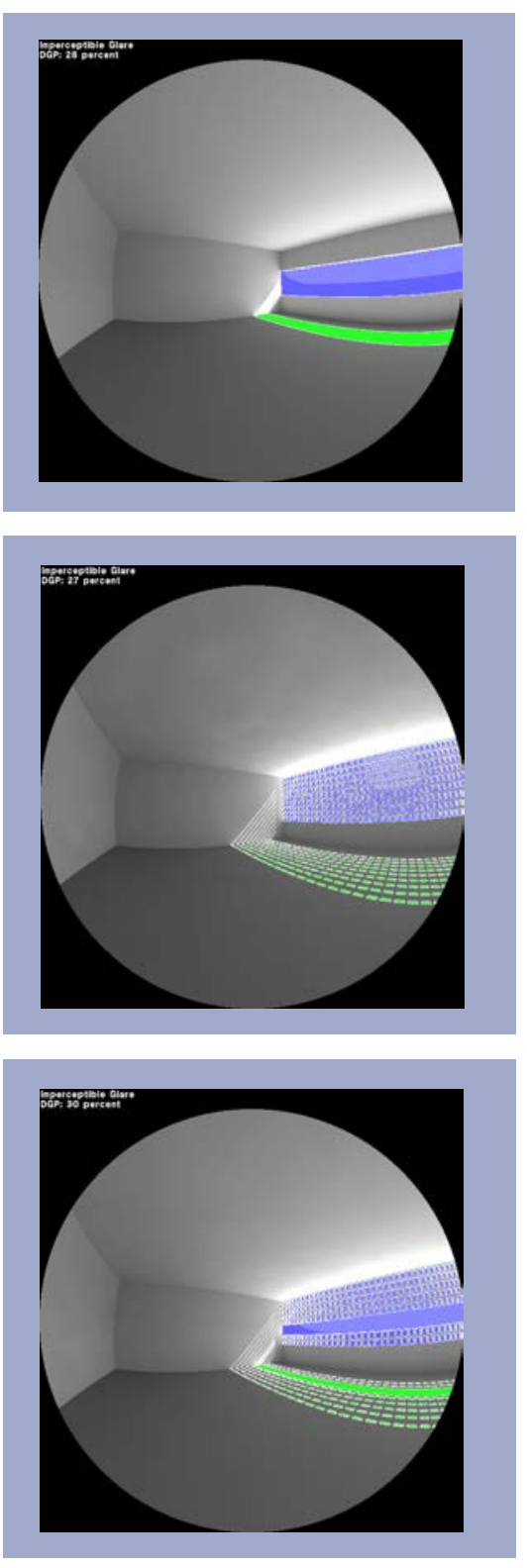
desde ambos observadores. Es decir, si

y contrastes en los campos visuales de los ocupantes de determinado espacio. Wienold (2010) recopila varios de estos modelos y propone una nueva métrica denominada Daylight Glare Probability (DGP), que tiene por objetivo estimar la probabilidad de deslumbramiento debida a la luz natural. Jakubiec y Reinhart (2012), en un análisis comparativo, encontraron que esta nueva métrica es más confiable que otras, pues posibilita las predicciones de manera razonable, bajo varias condiciones. Para identificar las porciones del campo visual que potencialmente contribuyen con la posibilidad de deslumbramiento, en el plugin de Diva se calculan imágenes denominadas point in time glare. Según la guía del usuario del programa (Lagios 2015), las áreas resaltadas representan las zonas del campo visual con alto contraste, es decir, valores de luminancia tres veces mayores que la luminancia promedio de la imagen. En la Imagen 7 se muestra este tipo de gráficos en los mismos ambientes y con idéntica localización de los observadores descritos anteriormente.

A pesar del valor de este tipo de análisis y de la ayuda que este tipo de imágenes puedan representar durante el proceso de diseño arquitectónico, resulta estratégico revisar el desempeño estudiado durante todo el año. En el plugin Diva for Rhino, las imágenes denominadas Daylight imageAnnual Glare muestran, hora a hora para un año, el nivel de deslumbramiento. En imagen 8 y en imagen 9 se resaltan en colores las épocas del año en las que el observador 1P1 y el observador 2-P2, respectivamente, podrían experimentar deslumbramiento imperceptible, deslumbramiento perceptible, deslumbramiento molesto 0 deslumbramiento intolerable (Lagios 2015). En términos generales, las diferencias existentes entre los resultados de las fachadas evaluadas son proporcionales 
bien hay diferencias entre los resultados encontrados en las posiciones P1 y P2, entre la fachada 1 y la fachada 2 de ambas posiciones se observan menores valores de DGP entre las $8 \mathrm{~h}$ y las $9 \mathrm{~h}$. (imagen 10). Cabe resaltar que la principal diferencia entre los resultados de ambas posiciones se evidencia entre los meses de noviembre y febrero, pues mientras que en la posición P1 no se registran significativos valores altos de DGP, en la posición P2 se aumentan ligeramente. Las imágenes producto de las simulaciones evidencian, para la fachada 1, alta frecuencia de valores de DGP, superiores a 0.45 entre las $6 \mathrm{~h}$ y las $7 \mathrm{~h}$ y una reducción entre las $7 \mathrm{~h}$ y las 9h. Entretanto, los resultados de la fachada 2 evidencian que esos altos valores de DGP se extienden una hora más, desde las 6 h hasta las 8 h. De acuerdo al ángulo de declinación solar propia de la latitud y a la geometría de las fachadas, se puede deducir que los altos valores de DGP en estas primeras horas de la mañana se deben a la exposición a la radiación solar directa, lo que deriva en una sensación de deslumbramiento incapacitante o disability glare.

Por otro lado, la reducción de los valores de DGP para la fachada 1 entre las 7 y y las 9h se explica en la reducción de valores predominantes de DGP mayores a 0.45 y a la predominancia de valores de DGP entre 0.35 y 0.4. De la misma forma, los resultados obtenidos para la fachada 2 evidencian que después de las 8 h se reducen casi definitivamente los valores de DGP, lo que implica menor probabilidad de deslumbramiento en la jornada escolar durante todo el año. Estas diferencias entre ambas fachadas evidencian la capacidad del muro calado para auto-sombrearse durante gran parte del tiempo y para reducir el contacto visual con la bóveda celeste; no obstante, debido a la distribución de aberturas a lo largo de toda la fachada, especialmente en la parte alta, también evidencian que los rayos solares podrían llegar hasta zonas más profundas del salón que en una sala con fachada convencional (fachada 1).

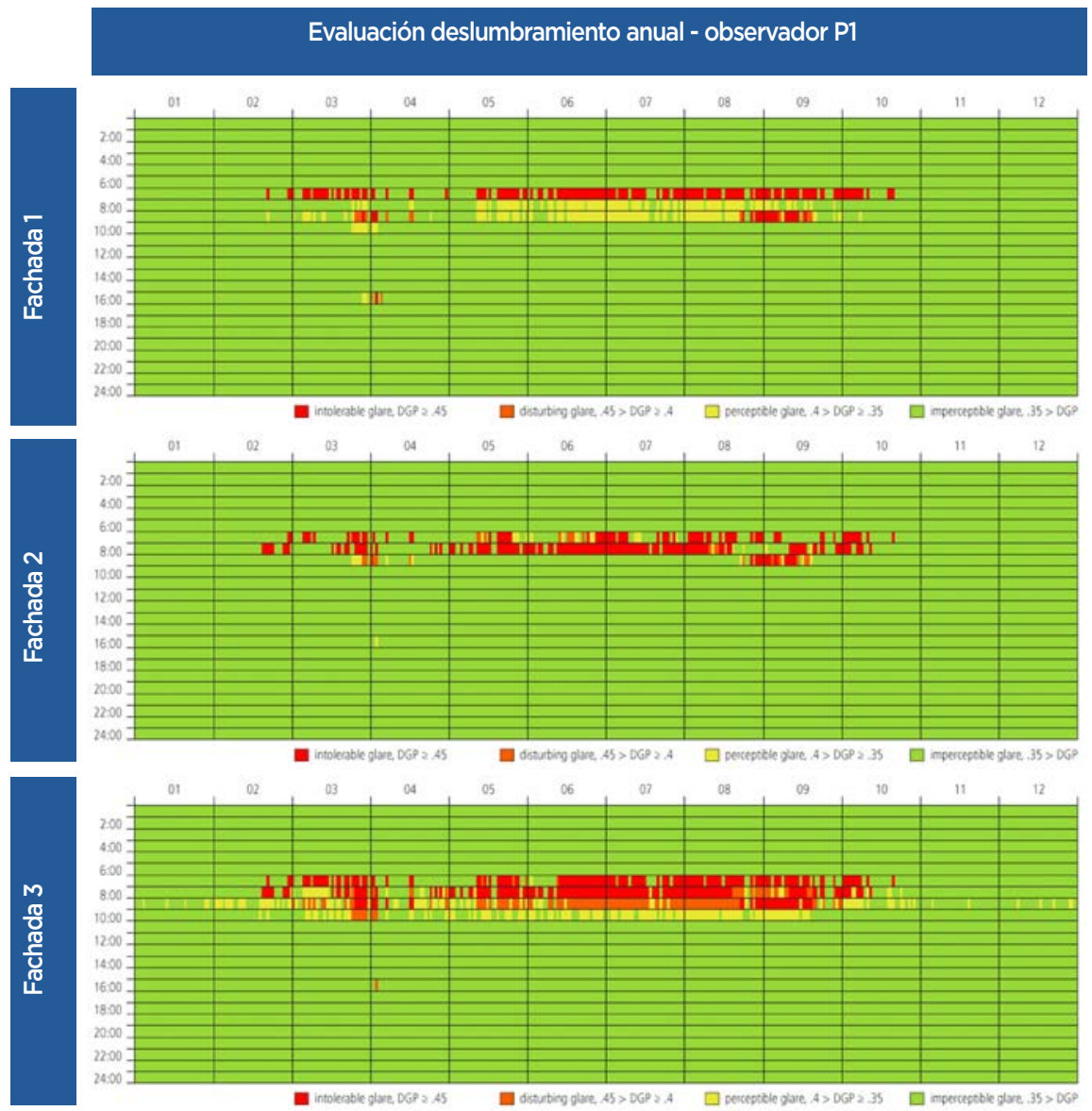

Imagen 8. Daylight image-Annual Glare. Análisis de la probabilidad de des/umbramiento a lo largo del año. Observador PI (fuente: Elaboración propia. Imagen generada haciendo uso del plugin Diva for Rhino).

Por último, la fachada 3, que combina las estrategias de las otras dos fachadas, posee mayores valores de DGP entre las $6 \mathrm{~h}$ y las $10 \mathrm{~h}$ pues, además de la exposición a la radiación solar directa durante las primeras horas de la mañana, posibilita el ingreso de rayos solares hasta las zonas más profundas del salón, al tiempo que permite la aparición de una franja considerable de bóveda celeste en el campo visual de los observadores entre las $8 \mathrm{~h}$ y las $10 \mathrm{~h}$ de gran parte del año. Asi, se observa que la fachada 3 posee un desempeño menos adecuado en términos de deslumbramiento.
CONCLUSIONES. Los beneficios

sicológicos, fisiológicos, económicos, etc del uso de la iluminación natural sobre la iluminación artificial en ambientes educativos y laborales son evidentes y cada vez más reconocidos. No obstante, la correcta implementación de la iluminación natural requiere una revisión cuidadosa, no solo en términos de garantizar la cantidad de luz para realizar determinada tarea visual, sino, entre otros, del control de brillos y contrastes en el campo visual de las personas. En ambientes educativos, la responsabilidad de este control recae directamente sobre la fachada. 
En este estudio, los muros calados como fachada de ambientes educativos demostraron tener potencial, en la medida en que su desempeño, en términos de control de probabilidad de deslumbramiento y admisión y distribución de la luz natural, resultó no distar mucho de aquel de ambientes educativos típicos. Esto significa que, además de las ventajas en términos térmicos que puedan llegar a existir sobre las fachadas convencionales, las fachadas demostraron tener potencial en términos de control visual.

A pesar de que es claro que estudios ampliados con otros tipos de fachadas perforadas, en otras orientaciones y/o con otros observadores, deberán ser realizados para certificar la idoneidad del uso de este tipo de sistemas en ambientes educativos localizados en lugares con climas cálidos, el reto para los diseñadores consiste en incorporar, tan temprano como sea posible en el proceso proyectual, reflexiones en la fachada que den garantía de la comodidad visual y térmica en ambientes educativos, que contribuyan con la optimización de los procesos pedagógicos

$\Delta 0$

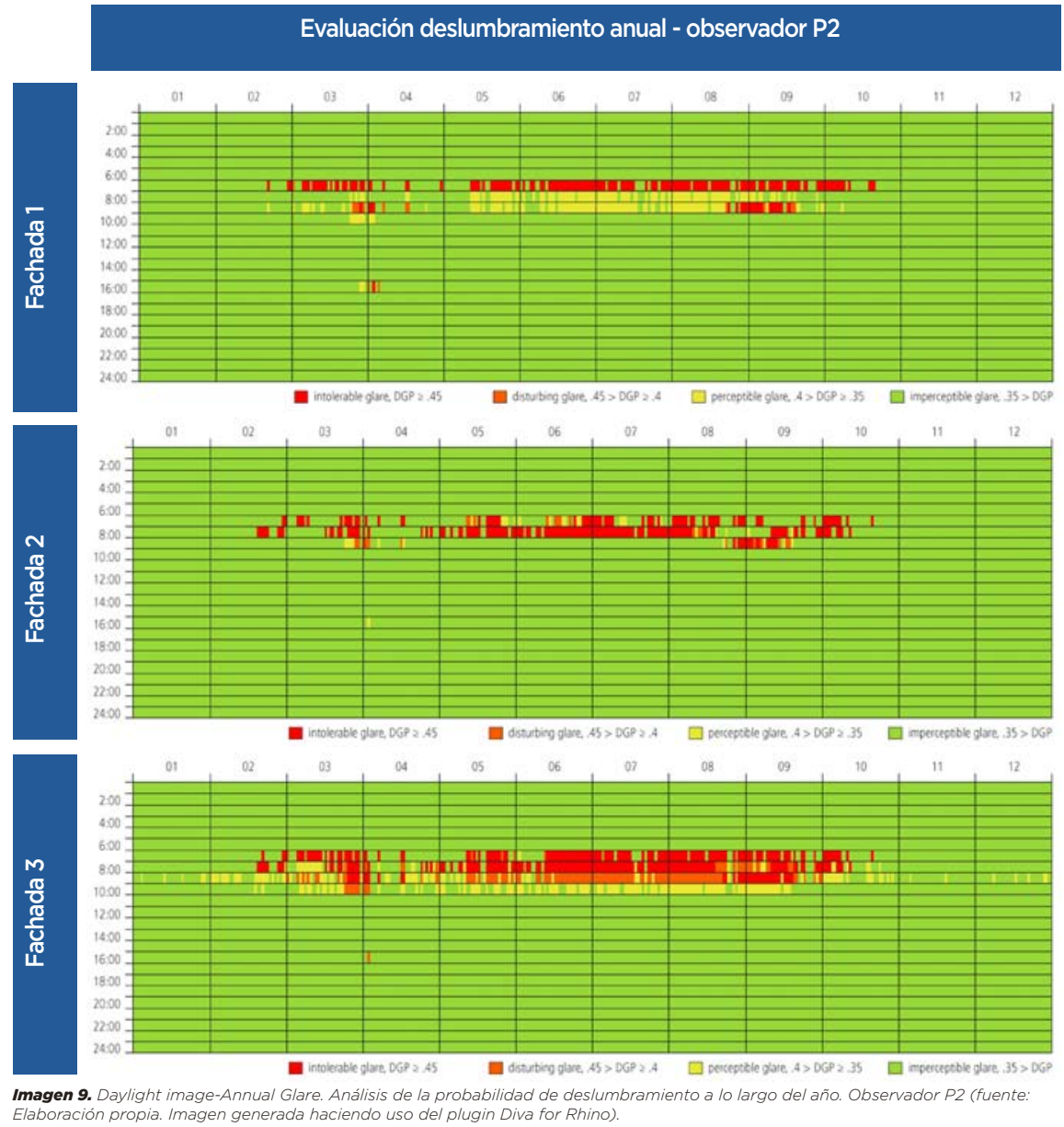
Imagen 9. Daylight image-Annual Glare. Análisis de la probabilidad de des/umbramiento a lo largo del año. Observador P2 (fuente:

\section{REFERENCIAS}

Aksamija, A., 2013. Sustainable Facades. Design methods for high-perfomance building envelopes. New Jersey: Wiley

Arango, L., Giraldo, N., Cano, L. y Arenilla, A., 2013. "Revisión de las recomendaciones de la NTC 4595 con relación a las aberturas de los salones de clase." Revista Dearq

Boubekri. M. 2008. Daylighting. Architecture and Health. Oxford: Elsevier.

Gulati, N., 2012. "Cost Effectiveness in HVAC by Building Envelope Optimization." AUS, 11

Hopkinson, R.. Petherbridge, P. y Longmore, J., 1966. //uminaçãa Natural. Lisboa: Fundação Calouste Gulbenkian.

Illuminating Engineering Society of North America, IESNA. 2000. The IESNA Lighting Handbook. Estados Unidos.

Jakubiec, J. y Reinhart, C. 2012. "The 'Adaptative Zone' - A concept for assessing discomfort glare throughout daylit spaces." Lighting Research and Technology, 44.

Lagios, K., 2015. Diva for Rhino. User Guide. Recuperado de http://diva4rhino.com/user-guide (09.04.15) Lamberts, R., Dutra, L. y Pereira, F., 2014. Eficiência Energética na Arquitetura. Brasil: Eletrobras y Procel. La Roche P. 2012 Carbon-Neutral Architectural Design Boca Raton. Taylor \& Francis Group.

Maslin, M., 2009. Global Warming. A very short introduction. Oxford: Oxford University Press.
Meek, C. y Van den Wymelenberg. K., 2015. Daylight and integrated lighting design. Oxon: Routledge. Norma Técnica Colombiana, NTC, 4595. (1999). Planeamiento y Diseño de Instalaciones y Ambientes Escolares. Icontec, Colombia.

Nunes, C., 2015. O uso do cobogó na arquitetura bioclimática. Recuperado de http://sustentarqui.com.br/ dicas/o-uso-do-cobogo-na-arquitetura-bioclimatica (15.06.15)

Ruggiero, F., Serra, R. y Dimundo, A., 2009, "Re-interpretation of traditional architecture for visual comfort." Building and Environment, 44 (9), 1886-1891.

Salazar. J., 2015. "Openwork Walls and Their Solar Applicability Range." Journal of Civil Engineering and Architecture, 9

Salazar, J. y Rendón, L., 2012. "Solar Control using Openwork Walls: The Solar Applicability Range." Anais Brasileiros De Dermatologia 7 (1), 1 - 6

Solemma, L., 2012. Diva for Rhino. Recuperado de http://www.solemma.net/index.html (19.04.15)

Steg, L., Vand Den Berg, A. y De Groot, J., 2013. Environmental Psychology. An Introduction. West Sussex British Psychology Society and John Wiley \& Sons.

Wienold, J., 2010. Daylight glare probability. Alemania: Fraunhofer Verlag. 